\title{
Acoustic water bottom investigation with a remotely operated watercraft survey system
}

\author{
Shintaro Yamasaki ${ }^{1 *}$, Tomonori Tabusa ${ }^{2}$, Shunsuke Iwasaki ${ }^{2}$ and Masahiro Hiramatsu'
}

\begin{abstract}
This paper describes a remotely operated investigation system developed by combining a modern leisure-use fish finder and an unmanned watercraft to survey water bottom topography and other data related to bottom materials. Current leisure-use fish finders have strong depth sounding capabilities and can provide precise sonar images and bathymetric information. Because these sonar instruments are lightweight and small, they can be used on unmanned small watercraft. With the developed system, an operator can direct the heading of an unmanned watercraft and monitor a PC display showing real-time positioning information through the use of onboard equipment and long-distance communication devices. Here, we explain how the system was developed and demonstrate the use of the system in an area of submerged woods in a lake. The system is low cost, easy to use, and mobile. It should be useful in surveying areas that have heretofore been hard to investigate, including remote, small, and shallow lakes, for example, volcanic and glacial lakes.
\end{abstract}

Keywords: Aquatic investigation, Echo sounding, Bathymetry, Fish finder, Remote operation, Unmanned watercraft

\section{Introduction}

Acoustic investigation by sonar is a basic scientific method that has been used to measure depth and investigate geological conditions under water. However, using this method has historically been costly and required researchers to have special training. Acoustic methods have also been used for commercial and leisure fishing, whether to find fish and fish beds or to prevent ships and boats from grounding. The performance of leisure-use fish finders has improved considerably recently. They provide high-quality depth measurements and high-resolution sonar images. In addition, the data are recordable with simultaneous positional information, so a wide range of scientific data can be collected at a relatively low cost; moreover, the equipment can be used on small boats because of their small size and light weight. Thus, these modern fish finders have been used in a variety of research fields, including marine engineering (Uchida et al. 2008; Tabusa et al. 2013), glaciology (Sugiyama et al. 2015),

\footnotetext{
* Correspondence: yamasaki@mail.kitami-it.ac.jp

${ }^{1}$ Kitami Institute of Technology, 165 Koen-cho, Kitami, Hokkaido 090-8507, Japan

Full list of author information is available at the end of the article
}

marine biology (Heyman et al. 2007), and archeology and geology (Yamasaki and Kamai 2015).

Because leisure-use fish finders are light and small, they have been used in trials on remote-controlled watercraft (e.g., Tedesco and Steiner 2011; Purdie et al. 2016). The surveys using them can perform acoustic investigations of small areas, including small lakes, ponds, and other areas unsuitable for normal manned vessels. Previous studies using remote-controlled watercraft and leisure-use fish finders mainly focused on measuring depth to produce bathymetric maps. By combining the use of a modern high-performance fish finder, which provides information on bottom materials and topographic details, and a remote-controlled watercraft, more detailed and broadbased analyses can be conducted in small water areas. In addition, these types of remote control systems can be developed by using recently developed, inexpensive commercial electronic devices. In this study, we developed a low-cost remote control system and evaluated its use on a remote-controlled watercraft equipped with a highperformance fish finder.

The developed watercraft is easy to produce, so we expect it could be used in a wide array of earth science 
fields. In this paper, we present a method of producing the system, a procedure for using it, and a case study of its use.

\section{Methods/Experimental \\ Sonar systems}

We used fish finders to provide sonar images, depth data, and synchronized positioning information via GNSS (global navigation satellite system). Sonar images differ depending on acoustic sources; 50 to $200 \mathrm{kHz}$ acoustic sources have usually been used in traditional fish finders. Although these frequencies emphasize fish finding, shapes are indefinite in the sonar images. Some GNSS fish finders, however, provide not only traditional sonar images (Fig. 1a) but also side-scan images or highresolution sonar images with higher frequency acoustic sources, for example, $455 \mathrm{kHz}$ (Fig. 1b). Side-scan imaging is a technology that can be used to survey wide areas and that can produce images of shape and dimensions (Fig. 1c). In this study, we looked for a sonar system that would transmit acoustic beams on two different frequencies as well as provide traditional acoustic images, high-resolution sonar images, and side-scan images simultaneously. We adopted two low-cost systems that consisted of the following components: a combination of a $\mathrm{HDS}^{\oplus}-5$ Gen 2, StructureScan ${ }^{\bullet}$ HD scanner (Lowrance Electronics, US), and a B60-12 $2^{\circ}$ transducer (Airmar Technology Corp., US) or a combination of the HDS $^{\circ}-7$ Gen 2 touch scanner (Lowrance Electronics) and a P319 transducer (Airmar Technology Corp.). StructureScan ${ }^{\circ}$ HD scanner is a machine of side-scan and high-resolution sonar to use with $\mathrm{HDS}^{\circ}-5$ Gen 2 . $\mathrm{HDS}^{\ominus}-7$ Gen 2 touch is a sonar machine that has functions of normal, high-resolution and side-scan sonars. The performance of both systems was quite similar, but the B60-12 transducer includes a function such that the acoustic beam is always shot straight down regardless of whether the vessel is rolling or not.

The frequency of the acoustic source is related to the sounding limit at a given power level. For example, lower frequencies reach a greater depth, but the resolution of
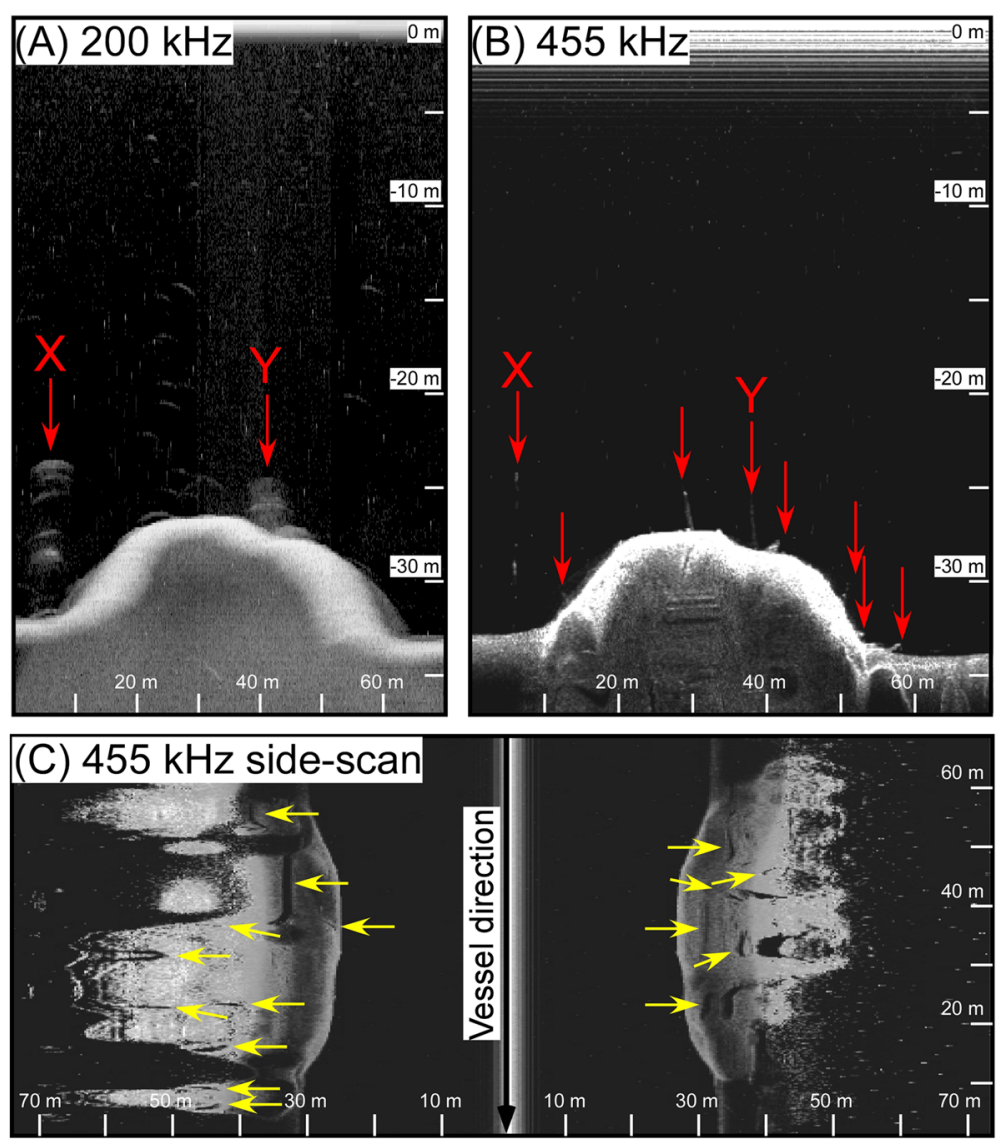

Fig. 1 Sonar images obtained by a a $200 \mathrm{kHz}$ acoustic source (P391 transducer, Airmar), b $455 \mathrm{kHz}$ acoustic source (StructureScan ${ }^{\bullet}$ HD, Lowrance), and c $455 \mathrm{kHz}$ side-scan (StructureScan ${ }^{\oplus}$ HD, Lowrance) for the same track. The red arrows indicate the submerged trees; $X$ and $Y$ on $\mathbf{a}$ and $\mathbf{b}$ are the same objects. Brighter images suggest stronger acoustic reflection. c Side-scan image shows the areal distribution of acoustic reflections on the lake floor; prominent materials on the floor are bright and their shadows are dark. Thus, the shape of materials on the floor is identifiable; for example, submerged trees (yellow arrows) have long shadows 
the sonar image worsens at lower frequencies (Fig. 1a, b). With the combination of the $\mathrm{HDS}^{\odot}-5$ Gen 2, Structure$\mathrm{Scan}^{\odot}$ HD scanner, and B60-12 ${ }^{\circ}$ transducer, we could detect objects at a depth of less than about $150 \mathrm{~m}$ with a $200 \mathrm{kHz}$ acoustic source, but we obtained $455 \mathrm{kHz}$ highresolution images only at depths of less than about $80 \mathrm{~m}$. Side-scan imaging by StructureScan ${ }^{\circledR} \mathrm{HD}$ with a $455 \mathrm{kHz}$ acoustic source is effective at depths of less than $60 \mathrm{~m}$ and widths narrower than $100 \mathrm{~m}$.

Acoustic beams are transmitted and received through transducers, and there are many types of transducers in terms of both power and acoustic frequency. An acoustic beam has a radiation angle, and the width of the scanned area at the bottom surface depends on depth. For example, if the radiation angle is $12^{\circ}$, the area of scanning is a circle $6 \mathrm{~m}$ in diameter at a depth of $30 \mathrm{~m}$, but it is $21 \mathrm{~m}$ in diameter at $100 \mathrm{~m}$. Because sonar systems measure distance from the closest point to the transducer, the detected depth is not always the true depth at the position of transducer. Thus, the radiation angle of transducer, depth range, and irregularity of topography should be considered in effective surveys.

We confirmed the accuracy of the previously noted fish finders by using a hand lead. The depths measured by the two systems were $0.2 \mathrm{~m}$ deeper than the true depth for a depth of $32.0 \mathrm{~m}$ and a water temperature of $8.2{ }^{\circ} \mathrm{C}$. However, we measured depth accuracy only under this one condition for each system. Therefore, the accuracy of each system still needs to be examined under a greater variety of conditions because acoustic velocity varies with water temperature and density.

\section{Remote-controlled vessel}

The developed remote-controlled vessels were equipped with the sonar system, GNSS receivers and a heading sensor, and an electric motor system (Fig. 2). Positioning and heading information were transmitted to the vessel from the operator on land, who could remotely control the heading and speed of the watercraft while monitoring its real-time position and path on a PC display. The concept of the overall system is based on Tabusa et al. (2013), but the developed system is simpler. Tabusa et al. (2013) developed a completely automated system in which watercraft pass through a number of GPS way points. For surveying shallow water areas and hazardous water areas, however, a semi-automated system such as ours can be more effective. For example, there are generally many obstructions in small water areas, and small watercrafts are easily affected by wavy and windy conditions, so having an operator remotely direct the heading of the vessel allows for more flexibility in avoiding obstructions. This flexibility allows the operator to select a safer or more easily navigable route when the watercraft is affected by obstacles, waves, or wind.

We used 12 V electric motors (Model 50700-120, Haswing, China), weighing about $15 \mathrm{~kg}$, on the remotecontrolled watercraft. Although each electric motor had a wireless controller, the communication distance of the

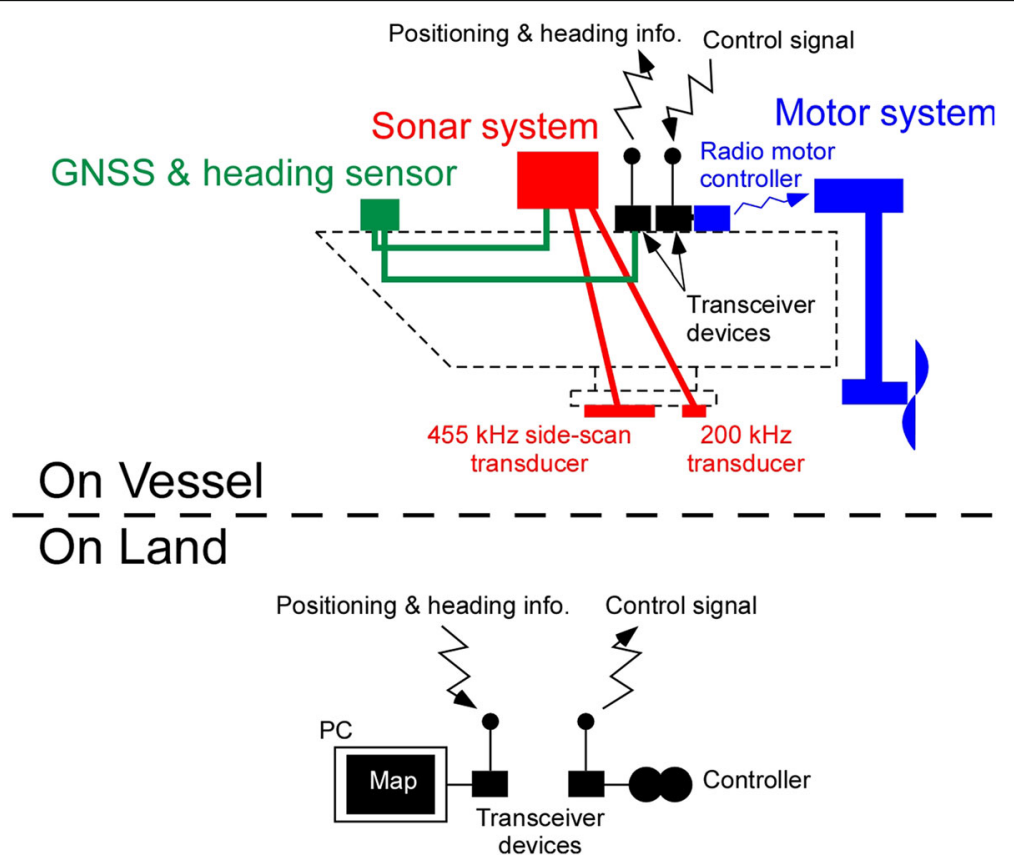

Fig. 2 The concepts behind the remote-controlled watercraft survey system. The watercraft has four systems: motor (blue), sonar (red), GNSS receiver and heading sensor (green), and transceiver (black). The positioning and heading information are transmitted to a PC on land, and the operator can watch the trace and real-time position on a PC display and transmit a signal to a radio controller to operate the craft 
controller was less than $50 \mathrm{~m}$. We attached a ZigBee 2.4 $\mathrm{GHz}$ device (XBee-PRO ${ }^{\curvearrowleft}$ 528, Digi International Inc., US) to the motor's wireless controller to increase the communication distance to about a maximum of $1.6 \mathrm{~km}$ in open air conditions.

To monitor position, speed, and heading direction of the watercraft in real time, we equipped the vessels with GNSS and a heading sensor device (Point-1 Antenna, Lowrance Electronics, US) and received the data through a similar long-distance transmission mechanism as described above. The real-time position, heading, and speed data (described in NMEA 0183 protocol) were processed by a microcomputer, then transmitted through a serial communication method using a ZigBee device. The total weight of the sonar, communication system, and battery was about $30 \mathrm{~kg}$. The data were received on land by another ZigBee device and transmitted to a PC through a serial port. The data were output and recorded in real time to show the path of the vessel on a PC display. We developed the monitoring software with Google $^{\mathrm{Tm}}$ Maps JavaScript API v3.

In designing the watercraft, the balance between weight and sturdiness against waves and winds needed to be considered. Unbalanced watercraft cannot run straight, which causes a loss of time and power in the watercraft's battery. We first used a box boat and an inflatable boat. They were easy to use and could carry a lot of materials on their decks. They were, however, unstable in wavy conditions and difficult to control. We then developed a twin-hulled watercraft to improve stability by using wood panels and plastic sheets (Fig. 3a and model $\mathrm{A}$ in Table 1). In this case, the transducers can be placed on the center of the watercraft, which is advantageous for both stability and data quality. We also developed a twin-hulled watercraft made with plastic floats, a wood board, and steel pipes (Fig. 3b and model $B$ in Table 1). This watercraft could easily be disassembled into small components for transportation.

\section{Analysis of subaqueous topography and surface geology}

The procedure to make bathymetric maps and analyze the bottom surface geology consists of three steps: (1) field work, (2) data processing, and (3) visualization.

\section{Field work}

To make a bathymetric map, the watercraft has to cruise a number of parallel tracks. Because fish finders use a single-beam echo sounder, a moving watercraft equipped with sonar can only make a depth profile. Thus, the resolution of the bathymetric map depends on the interval between the tracks. The length of the interval, however, is restricted by the scanning range of the acoustic beam, which increases with depth. The researcher has to adjust the cruise speed appropriately. If the speed is too high, the measured depth may be mismatched with the true depth, particularly when measuring steep slopes.

\section{Data processing}

Sonar data were recorded in the SD card in the fish finder. To make a bathymetric map, it is necessary to extract position and depth data from the sonar data. Recently, lowcost GIS software that displays and analyzes sonar image data has become commonly available (e.g., ReefMaster Pro, ReefMaster Software Ltd., UK; SonarTRX, Leraand Engineering Inc., USA). These software packages have functions that synchronize position and sonar images, detect depth from sonar images, and generate matrices including positions and depth as CSV files.

With some processing software, an analysis of bottom materials is also possible by using the properties of
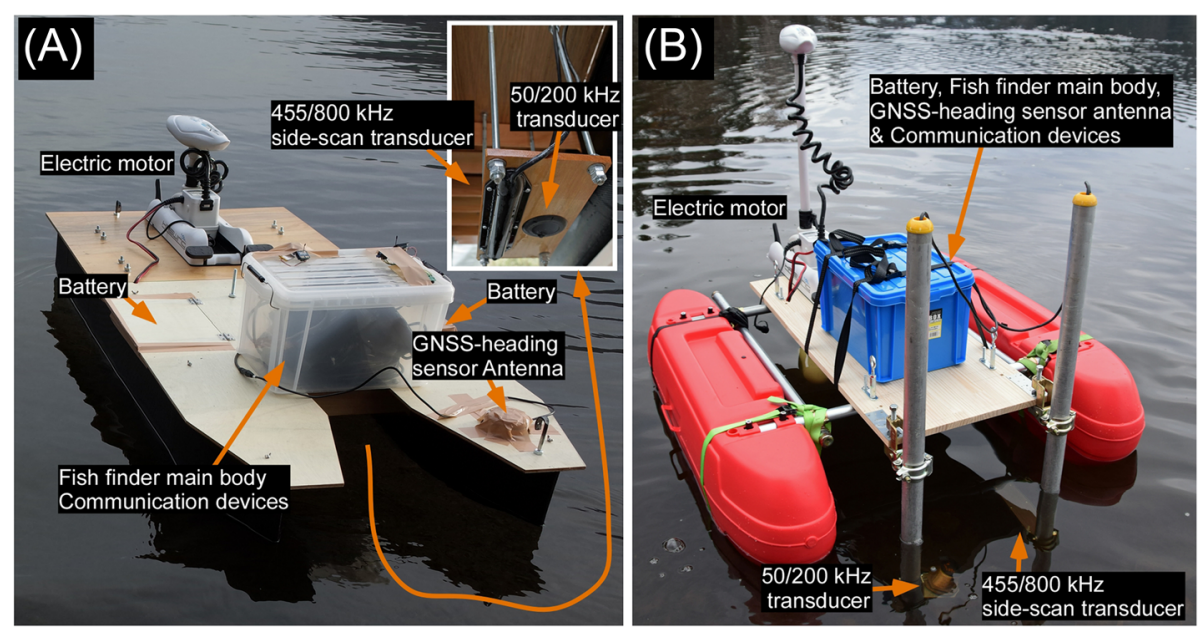

Fig. 3 The developed twin-hulled watercraft: a a model made with a wood frame and waterproof plastic sheets and $\mathbf{b}$ a model made with plastic floats, a wood platform, and steel pipes 
Table 1 Specifications of the developed unmanned watercraft

\begin{tabular}{llc}
\hline Watercraft & Model A & Model B \\
\hline Length & $1.2 \mathrm{~m}$ & $1.3 \mathrm{~m}$ \\
Width & $1.0 \mathrm{~m}$ & $1.1 \mathrm{~m}$ \\
Total weight & $60 \mathrm{~kg}$ & $45 \mathrm{~kg}$ \\
Propulsion & & Electric motor \\
Energy & $2 \times 12 \mathrm{~V}$ lead battery $\quad 1 \times 12 \mathrm{~V}$ lead battery \\
Operational speed & & $3-5 \mathrm{~km} / \mathrm{h}$ \\
\hline
\end{tabular}

return signals. The return signal detected by a fish finder is a combination of multiple echoes. The first echo is strongest at the bottom surface, and the echo gradually attenuates. The second echo, which is caused by a reflection on the water surface or boat hull, appears from about twice the depth of the first echo and it also attenuates (Fig. 4). Chivers et al. (1990), Kloser et al. (2001), Lawrence and Bales (2001), Collier and Brown (2005), Penrose et al. (2005), and others have extracted the E1 and E2 indices from these echoes and successfully classified bottom materials by comparative analysis. As shown in Fig. 4a, the tail part of the first echo is E1 and the entire second echo is E2. The E1 index is a measure of the roughness of the bottom surface, and the E2 index is a measure of hardness of the bottom surface. E1 and E2 are recognized as layers on the sonar images (Fig. 4b).

Bottom analysis using E1 and E2 layers has been semiempirically established. Chivers et al. (1990) and Lawrence and Bales (2001) explained E1 and E2 as follows: in the case where the bottom is rough, the reflections transmit from various angles and form the E1 part. The first part of first echo is not included for the calculation, because it contains ambiguous sub-bottom reverberations. The second echo (E2) is formed by the signal that is reflected twice from the bottom and once from the water surface. Through these processes, specular reflections to the transducer from the bottom are formed and the reflection energy is a direct measurement of acoustic impedance. Because acoustic impedance is the product of density and sound velocity at the bottom surface, E2 is a measure of hardness.

We analyzed the layers automatically by using the software package ReefMaster Pro ver. 1.8. This software can also calculate a peak reflection strength in the first echo as a hardness value (in this software package, this value is referred as peak SV, Fig. 4). The E1, E2, and peak SV values are relative values within the same sonar image, and they are not comparable with other values from other images.

We confirmed by underwater camera observation that rugged bottom surfaces showed higher E1, E2, and peak SV values than smooth sandy surfaces. However, because few studies using leisure-use fish finders have conducted sonar analysis with ReefMaster Pro, more study is needed to confirm reliability under various conditions.

\section{Visualization}

The CSV data include longitude, latitude, depth, E1 value, E2 value, and peak SV value. To visualize them, we used 3D visualization software (Surfer 12, Golden Software LLC, USA). Since latitude and longitude are in degrees, we converted latitude and longitude into an equidistant projection that interpolates discrete data by the Kriging method to create grid data and the contour maps.

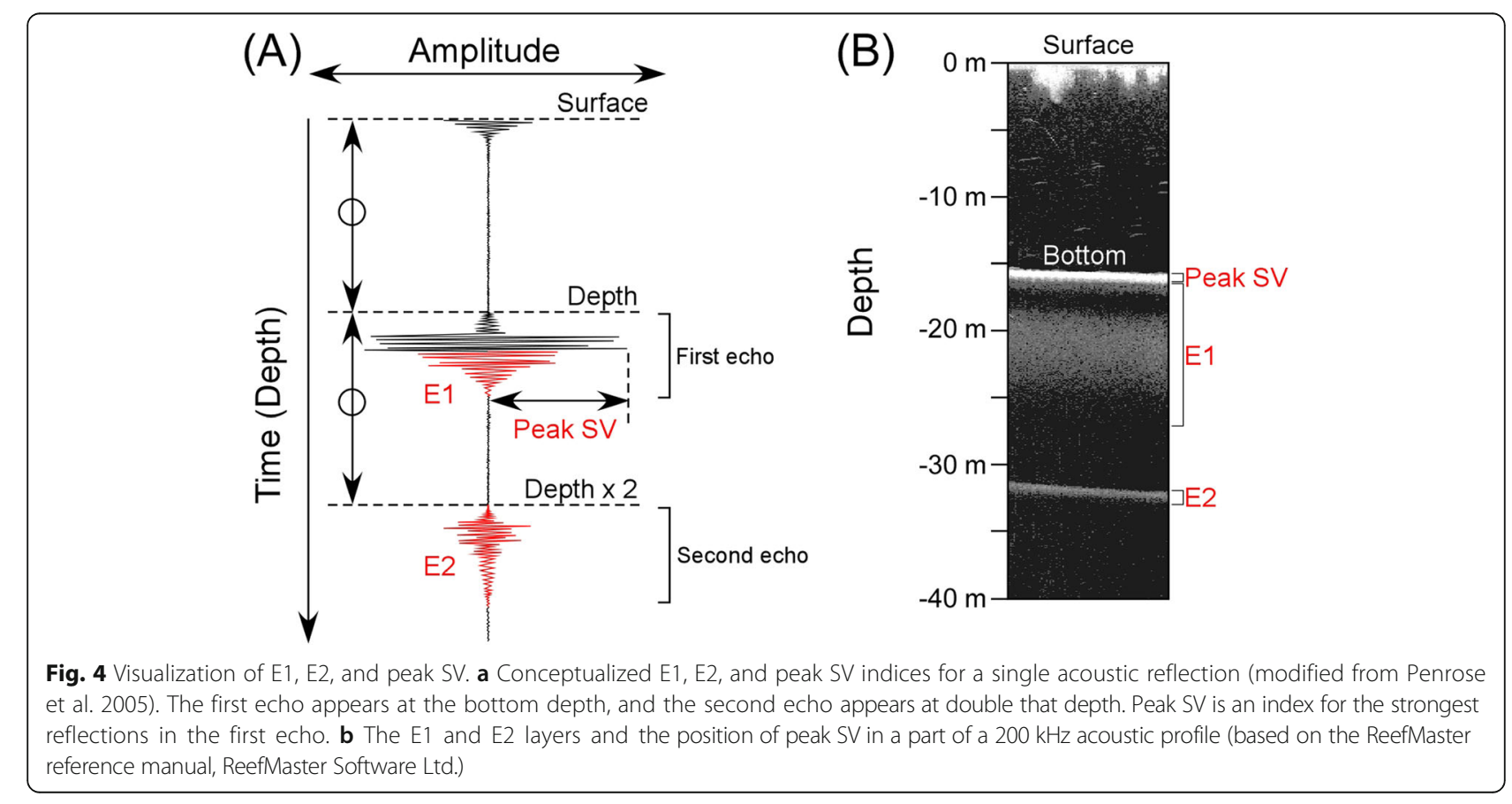




\section{A case study of the Ashinoko submerged wood area Background}

Lake Ashinoko (Fig. 5) is a dammed lake formed by the collapse of a volcano. Researchers generally agree that lake formation started about 3000 years ago on the basis of geologic evidence and carbon dating, for example, Oki and Hakamada (1975) dated a piece of wood in the dammed deposit at $3100 \pm 90$ year B.P. However, many submerged trees have been found in the areas that have much younger ${ }^{14} \mathrm{C}$ dates. For example, in the north part of the lake, a number of trees standing and lying on the lake bottom at a depth of about $30 \mathrm{~m}$ have been dated; their ${ }^{14} \mathrm{C}$ dates are $1610 \pm 35,1530 \pm 56$ (Kihara Institute of Biology 1974), and $2110 \pm 110$ year B.P. (Oki et al. 1988). Oki et al. (1988) and Oki (1993) inferred that the hills and submerged trees were deposited by a landslide.

We presumed the distribution of trees would have distinctive characteristics and that the base geologic materials would differ from those of muddy lake sediments if a landslide had occurred and investigated the area with our remotely operated watercraft system.

We used the watercraft made with a wood frame and waterproof plastic sheets (model A in Table 1 and Fig. 3a) and a combination of the HDS -7 Gen 2 touch and P319 transducer. The watercraft scanned about $2.5 \mathrm{~km}$, collecting 200 and $455 \mathrm{kHz}$ high-resolution sonar images and $455 \mathrm{kHz}$ side-scan sonar images. The investigation covered about 4 ha, and the watercraft's speed was maintained at about $3 \mathrm{~km} / \mathrm{h}$. The duration of survey using the system was about $1 \mathrm{~h}$.

\section{Results}

We obtained high-quality sonar images similar to those would be obtained in a manned operation (Fig. 1). Sidescan sonar imaging and high-resolution sonar imaging clarified that most of the submerged trees were distributed on the topographic rises (Figs. 1 and 5). The sidescan sonar covered the entire area, but it was difficult to identify the trees using side-scan sonar only because many of the trees were too small to be clearly identifiable. Thus, the distribution map of the submerged trees in Fig. 5 is not completely comprehensive, but it does show general tendencies.

Although some of the contour lines in the bathymetric map have unrealistic curvature, the topography of the rises is clearly identifiable (Fig. 5). A comparison of bottom material data (Fig. 6) shows the E1-roughness value is generally higher on steep slopes, whereas the E2-hardness and peak SV-hardness values are generally higher on the rises. By the way, those values are numerical, but the actual bottom material data are qualitative and show somewhat discontinuous features. We therefore displayed bottom material data by using color gradations on the map. Because acoustic beams reflect off the bottom with a circular form, the bottom material data are represented by the colored circles shown in the figure. There are no bottom material data for the gaps between the circles. We did not obtain the data to fill the gap; however, narrower scanning than the acoustic reflection area could provide complete coverage of the bottom. Although there were

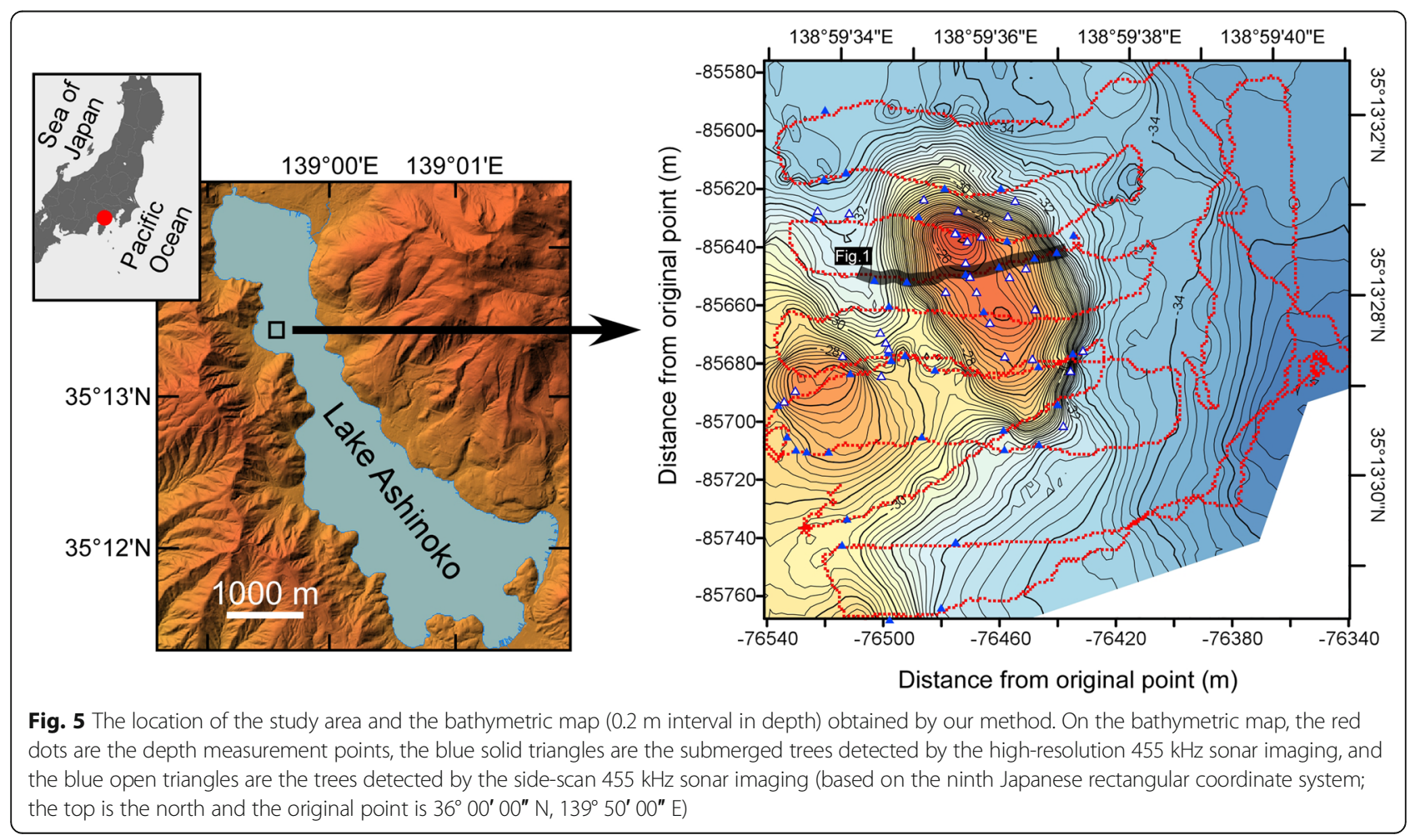



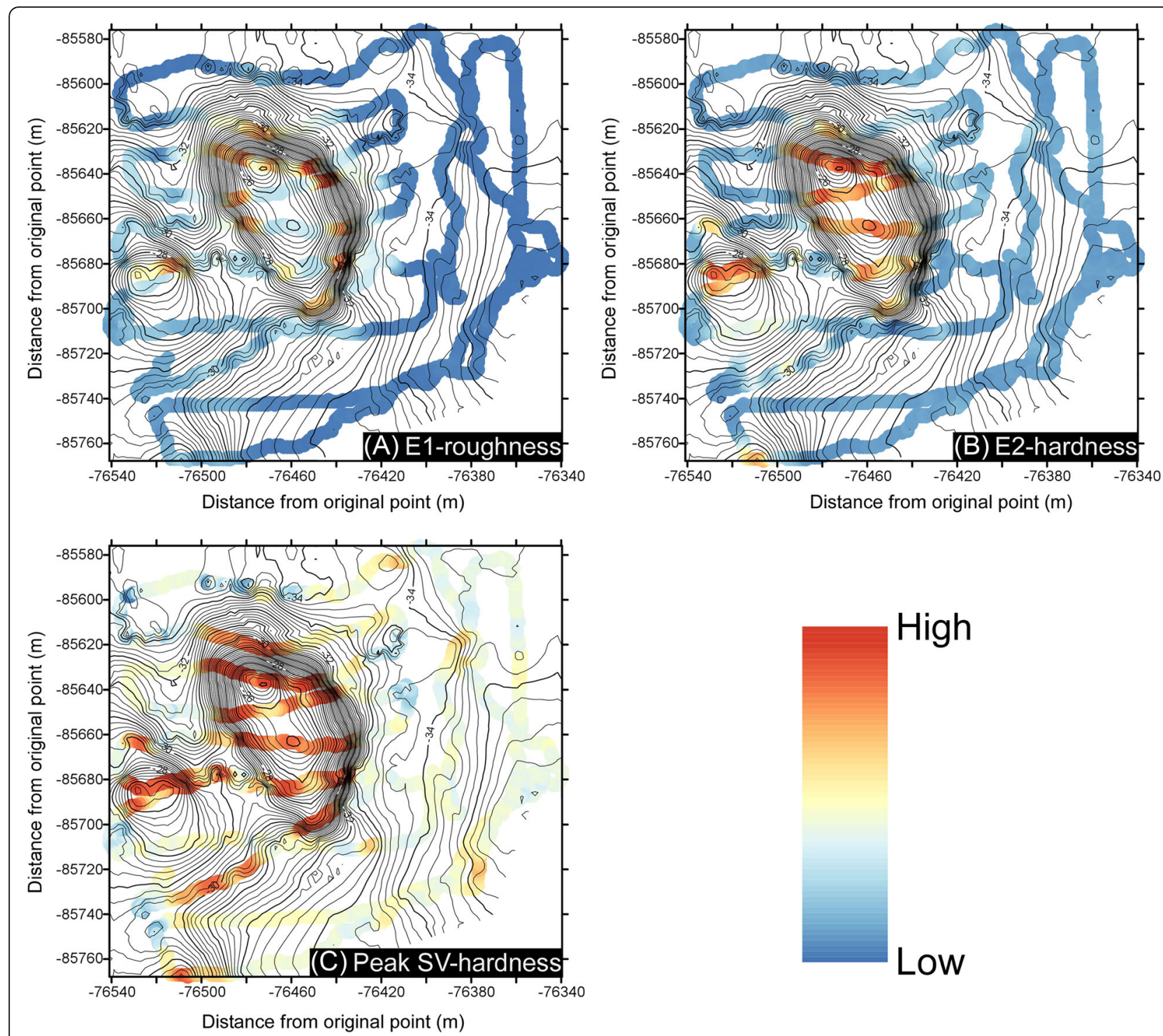

Fig. 6 The results of acoustic bottom analyses obtained by using a $200 \mathrm{kHz}$ acoustic source: a E1-roughness value, $\mathbf{b}$ E2-hardness value, and c peak SV-hardness value. The results are shown with colored solid circles $6 \mathrm{~m}$ in diameter (the area of scanning at a depth of $30 \mathrm{~m}$, the average depth in this area)

many anomalies in the values, the bottom materials on the rises were generally observed to be harder than those in the other parts of the lake. The fact that the rises and bases of submerged trees consist of hard materials is consistent with that of the idea that they had been transported via a landslide. The area with high E1 values could have been formed by secondary small landslides on steep slopes, and/or the deposition of lake sediments could have been slow on steep slopes.

\section{Discussion}

We introduced an investigation method using the combination of a remote-controlled watercraft survey system and a modern leisure-use GNSS fish finder. Here, we discuss prospects for future studies and problems.

As we mentioned, the greatest advantage of this method is its mobility and much lower cost than existing specialized scientific investigative methods. The investigation of small lakes and ponds has heretofore been difficult, but it nonetheless can be important for hazard prediction if abnormal phenomena are thought to occur in these areas. For example, the color of crater lake water suddenly changed in an active volcano (Mt. Zao, Japan) in 2014, but it has been difficult to distinguish whether the phenomenon was related to a volcanic event. Gas emissions from the sea or lake floor have been observed by using fish finders (e.g., Merewether et al. 1985), so it is possible that observation of gas 
emissions from volcanic lakes could be feasible by using our proposed method. In addition, observations and investigations of glacial lakes and lakes dammed by landslides are also feasible with this method. These types of lakes can pose a high risk of flooding for residents, so that prompt investigation of the topography of the dams is needed for hazard mitigation. However, water in volcanic lakes and glacial lakes is often turbid and from the air, so acoustic sounding is necessary for these types of investigations. In addition, these small lakes are generally remote and inaccessible, so conducting investigations with our proposed system should prove useful and effective.

The watercraft of Tedesco and Steiner (2011) and Purdie et al. (2016) used small water jet systems, so the vessels could be relatively flat and have a small risk of grounding. Smaller vessels also have a lower risk of grounding, and smaller sonar systems can be mounted on them. We used normal $12 \mathrm{~V}$ electric motors designed for use on manned vessels, so their drafts were slightly deeper, and unsuitable for use at depths of less than $1 \mathrm{~m}$. We also used a high-performance fish finder system with two transducers, which consumed more electricity than a smaller fish finder would. The developed system prioritizes not only cost-effective and productive vessels but also the collection of plentiful acoustic data.

The utilization of fish finders does have limitations. The beam width of fish finders is larger than that of expert-use echo sounders or multi-beam echo sounders, thereby restricting the resolution of the obtained bathymetry. The resolution and accuracy of the bathymetry also depends on the accuracy of GNSS positioning. However, this method provides sonar images with a high enough resolution to detect trees as small as several tens of centimeters in diameter. In our investigation (data not reported), we also detected ropes and nets during surveys.

Improved high-performance fish finding systems are continuously coming onto the market. Before they are installed for this type of use, researchers need to check their accuracies and sonar imaging properties.

\section{Conclusions}

We described an investigation method for subaqueous topography and geology by using a remote-controlled unmanned watercraft and modern leisure-use GNSS fish finders. In our method, the watercraft has an electric motor controlled by a land-based operator via a longdistance communication device. The operator directs the heading of the watercraft while monitoring a realtime positioning and a trace on a PC display. The obtained sonar images detect objects as small as several tens of centimeters in diameter with a true shape. By processing the data, we were able to produce a bathymetric map and maps of hardness and roughness of bottom materials in a case study area. The method is simple, is mobile, and of quite low cost, and it allows investigations of inaccessible water areas or high-risk areas, including volcanic lakes and glacial lakes.

\section{Acknowledgements}

We developed the method presented in this paper with the assistance of the Technical Division and Engineering Center of the Kitami Institute of Technology. Shin Sugiyama of the Institute of Low Temperature Science, Hokkaido University, gave us useful information and assisted our study in many ways. We are grateful for their assistance.

\section{Funding}

This work was supported by the Japan Society for the Promotion of Science KAKENHI Grant Numbers 23710206 and 26560187 and the Arctic Challenge for Sustainability Project, Japan.

\section{Authors' contributions}

SY proposed, conceived, and designed the study and analyzed the data. $\pi$ mainly developed the long-distance communication and controlling system and collaborated with SY in writing the manuscript. SI and MH mainly developed the watercraft. All authors read and approved the final manuscript.

\section{Competing interests}

The authors declare that they have no competing interests.

\section{Publisher's Note}

Springer Nature remains neutral with regard to jurisdictional claims in published maps and institutional affiliations.

\section{Author details}

${ }^{1}$ Kitami Institute of Technology, 165 Koen-cho, Kitami, Hokkaido 090-8507, Japan. ${ }^{2}$ National Institute of Technology, Yuge College, 1000 Shimoyuge,

Yuge, Kamijima-cho, Ochi-gun, Ehime 794-2593, Japan.

Received: 6 January 2017 Accepted: 21 August 2017

Published online: 08 September 2017

\section{References}

Chivers R, Emerson N, Burns D (1990) New acoustic processing for underway surveying. Hydrogr J 56:9-17

Collier JS, Brown CJ (2005) Correlation of sidescan backscatter with grain size distribution of surficial seabed sediments. Mar Geol 214:431-449

Heyman WD, Ecochard JLB, Biasi FB (2007) Low-cost bathymetric mapping for tropical marine conservation - a focus on reef fish spawning aggregation sites. Mar Geod 30:37-50

Kihara Institute of Biology (1974) Fundamental survey for the national forests in Hakone district. Tokyo regional forestry office. (in Japanese, title in translation)

Kloser R, Bax N, Ryan T, Williams A, Barker B (2001) Remote sensing of seabed types in the Australian South East Fishery; development and application of normal incident acoustic techniques and associated 'ground truthing'. Marine and Freshwater Res 52:475-489

Lawrence M, Bales C (2001) Acoustic ground discrimination techniques for submerged archaeological site investigations. Marine Technology Society J 35(4):65-73

Merewether R, Olsson MS, Lonsdale P (1985) Acoustically detected hydrocarbon plumes rising from 2-km depths in Guaymas Basin, Gulf of California. J Geophys Res Solid Earth 90(B4):3075-3085

Oki Y (1993) Fossil cedar trees of Lake Ashi as fossils of large earthquakes in Southern Kanto District. J Geogr (Chigaku Zasshi) 102:437-444 (in Japanese)

Oki Y, Hakamada K (1975) Exploring the birth of Lake Ashinoko, Hakone. Land and Education (Kokudo-To-Kyoiku) 30:2-9 (in Japanese, title in translation)

Oki Y, Hakamada K, Ito H (1988) Fossil cedar trees of Hakone (Hakone-noSakasasugi)-Kanashin Books 23. Kanashin publishing company. (in Japanese, title in translation)

Penrose J, Siwabessy P, Gavrilov A, Parnum I, Hamilton L, Bickers A, Brooke B, Ryan D, Kennedy P (2005) Acoustic techniques for seabed classification. Cooperative Research Centre for Coastal Zone Estuary and Waterway Management, Technical Report, 32 
Purdie H, Bealing P, Tidey E, Gomez C, Harrison J (2016) Bathymetric evolution of Tasman Glacier terminal lake, New Zealand, as determined by remote surveying techniques. Glob Planet Chang 147:1-11

Sugiyama S, Sakakibara D, Tsutaki S, Maruyama M, Sawagaki T (2015) Glacier dynamics near the calving front of Bowdoin Glacier, northwestern Greenland. J Glaciol 61(226):223-232

Tabusa T, Sawamura K, Mukai T, Kuzume K (2013) Development of small scanning boat by automatic cruise and making of 3-dimensional topography of Mekong River. Navigation 186:15-23 (in Japanese, title in translation)

Tedesco M, Steiner N (2011) In-situ multispectral and bathymetric measurements over a supraglacial lake in western Greenland using a remotely controlled watercraft. Cryosphere 5(2):445-452

Uchida K, Miyamoto Y, Takeda S, Tokai T, Kakihara T, Shiode D (2008) A facile method for mapping bathymetric chart at shallow coastal water by using GPS and fish finder. Fisheries Eng 45:93-100

Yamasaki S, Kamai T (2015) A novel method of surveying submerged landslide ruins: case study of the Nebukawa landslide in Japan. Eng Geol 186:28-33

\section{Submit your manuscript to a SpringerOpen ${ }^{\bullet}$ journal and benefit from:}

- Convenient online submission

- Rigorous peer review

- Open access: articles freely available online

- High visibility within the field

- Retaining the copyright to your article

Submit your next manuscript at $\gg$ springeropen.com 